\title{
Thyrotropin releasing hormone in hypovolemia: a hemodynamic evaluation in the rat
}

\author{
ANNA-LEENA SIRÉN, ELIZABETH POWELL, AND GIORA FEUERSTEIN \\ Department of Neurology, Neurobiology Research Division, Uniformed Services University of Health \\ Sciences, Bethesda, Maryland 20814-4799
}

Sirén, AnNa-Leena, Elizabeth Powell, and Giora FEUERSTEIN. Thyrotropin releasing hormone in hypovolemia: a hemodynamic evaluation in the rat. Am. J. Physiol. 250 (Heart Circ. Physiol. 19): H1093-H1101, 1986.-In the present study the effects of thyrotropin releasing hormone (TRH) and its stable analogue, CG3703, on cardiac output (thermodilution, Cardiomax) and regional blood flow (BF; directional pulsed Doppler technique) were investigated in hypovolemic hypotension in the rat. In urethan-anesthetized rats TRH $(0.5$ or $2 \mathrm{mg} /$ $\mathrm{kg} \mathrm{ia})$ or CG3703 (0.05 or $0.5 \mathrm{mg} / \mathrm{kg}$ ia) reversed the bleeding (27\% of the blood volume)-induced decreases in mean arterial pressure (MAP) and cardiac index (CI) and increased the heart rate (HR) and total peripheral resistance index (TPRI) in a dose-related manner. In the conscious rat exposed to a $45 \%$ hemorrhage, CG3703 (0.5 mg/kg ia) significantly raised MAP, $\mathrm{HR}$, and TPRI with maximum changes of $+67 \pm 6$ (SE) $\mathrm{mmHg}$, $+123 \pm 30$ beats/min, and $+101 \pm 2 \%$, respectively. CG3703 $(0.5 \mathrm{mg} / \mathrm{kg} \mathrm{ia})$ also further enhanced the hemorrhage-induced reduction of hindquarter, mesenteric, and renal $B F$. The changes in BF in saline-treated vs. CG3703-treated rats $2 \mathrm{~h}$ after the bleeding were $-32 \pm 6$ vs. $-55 \pm 6 \%(P<0.001)$ in hindquarter, $-9 \pm 8$ vs. $-61 \pm 11 \%(P<0.001)$ in mesenteric, and $-2 \pm 9$ vs. $-33 \pm 9 \%(P<0.01)$ in the renal artery; the changes in vascular resistance $+30 \pm 7$ vs. $+309 \pm 167 \%(P<$ 0.001 ) in hindquarter, $-4 \pm 8$ vs. $+349 \pm 244 \%$ in the mesenteric, and $-10 \pm 9$ vs. $+80 \pm 10 \%(P<0.01)$ in the renal artery. The survival rate after the $45 \%$ hemorrhage was significantly reduced by both TRH and CG3703. The results suggest that $\mathrm{TRH}$ reverses the hypovolemic hypotension mainly by increasing vascular resistance and causing impairment of BF to vital organs, thereby exacerbating the shock and leading to an increased mortality.

cardiac output; total peripheral resistance; regional blood flow

THYROTROPIN RELEASING HORMONE (TRH) is a tripeptide found in cell bodies and nerve fibers of mammalian brain and spinal cord (for review see Ref. 20). In addition to its endocrine effects, TRH induces strong cardiorespiratory stimulation that is of central origin $(2,5,8,16)$. Recent studies have shown that TRH is able to antagonize the hypotension in various experimental shock models (for review see Ref. 3). Systemic injection of TRH following endotoxic or hemorrhagic shock in the rat significantly improved the cardiovascular function $(13,15)$. TRH also reversed hypotension induced by leukotriene (LT) $\mathrm{D}_{4}$, platelet activating factor, soybean lipoxygenase, or antigen-induced anaphylaxis in the conscious guinea pig $(7,17,18)$.
The beneficial effect of TRH in experimental shock appears to be due to an action on the central nervous system, since doses of TRH that have no effect after sytemic injection reverse shock (14) and improve survival (1) after intracerebroventricular administration. Furthermore, the pressor effect of TRH on $\mathrm{LTD}_{4}$-induced hypotension is totally abolished in the pithed rat in which the complete central nervous system is destroyed (9). In intact rats, TRH induces marked rises of plasma levels of norepinephrine and epinephrine $(4,8)$, and, at least in endotoxic shock in the rat, the reversal of hypotension by TRH seems to require a functioning adrenal medulla (14). Recently, the beneficial effect of TRH on survival following anaphylactic shock in mice was also found to be mediated by the sympatho-adrenomedullary system (1). In some models of experimental shock, a physiological antagonism of the endogenous opioids by TRH has also been suggested (for review see Ref. 6). However, little is known of the discrete hemodynamic mechanisms underlying the effects of TRH in circulatory shock. We now report the effects of systemically injected TRH on cardiac output and total peripheral resistance following hemorrhagic shock in both anesthetized and conscious rats. Because TRH is rapidly inactivated after systemic administration (20), the effect of a degradation stable TRH analogue, CG3703 (10), on these variables was also examined. Furthermore, the effect of CG3703 on regional blood flow distribution and on blood gases and lactate after bleeding was investigated in the conscious rat. Earlier studies have shown that CG3703 is more potent than TRH in eliciting neuropharmacological effects such as activity in antidepressant screening tests, reversal of the effects of diverse central nervous system depressants, and promoting arousal when given alone, but it appears to be equipotent to TRH in endocrine tests $(10,19)$.

\section{MATERIALS AND METHODS}

Male Sprague-Dawley rats (260-360 g) were used in all experiments. After surgical operations, the chronically instrumented animals were housed individually in plastic cages $(21 \times 27 \times 16 \mathrm{~cm}, W \times L \times H)$ with food and water ad libitum.

\section{Measurement of Cardiac Output}

The cardiac output was measured by the thermodilu- 
tion technique (Cardiomax), which, due to its methodological simplicity, is useful in conscious rats. It has been shown previously that the cardiac output values obtained by this method correlate well with the cardiac output values obtained by electromagnetic flowmetry in the rat (24). The rats were anesthetized with urethan $(1.2 \mathrm{~g} / \mathrm{kg}$ ip), and PE-50 tubing was inserted into the femoral arteries. An incision was then made at the midline of the neck from the cricoid to the clavicle, and PE-50 tubing was inserted into the right atrium through the external jugular vein. The left common carotid artery was exposed and ligated. A reusable Teflon thermistor (MX2-780-33 model THMP f 1.5, Columbus Instruments, Columbus, $\mathrm{OH})$ was advanced through the carotid artery and into the ascending aorta (placement above the aortic valve was confirmed in each animal at the end of the experiment and by the shape of the dilution curve before the probe was finally sutured to the neck muscles). One arterial line was connected to a pressure transducer (Narco RP 1500i), and recordings of blood pressure (systolic, diastolic, mean) and heart rate were carried out by the Narcotrace 80 computerized dynograph. The cardiac output was measured by thermodilution technique with the thermistor attached to the computerized Cardiomax II (CMx2-780-k with the microprobe option $\mathrm{R}$, Columbus Instruments). The dead space of the venous line was first flushed with $0.05 \mathrm{ml}$ of $0.9 \%$ (wt/vol) $\mathrm{NaCl}$ (saline) at room temperature, $22^{\circ} \mathrm{C}$; after a brief stabilization period (10 $\mathrm{s}$ to ensure normal core temperature) an additional injection of $0.2 \mathrm{ml}$ normal saline $\left(22^{\circ} \mathrm{C}\right)$ was rapidly injected using a 1-ml syringe. Cardiac output was recorded by the following method: a control period of 30 min included two to three cardiac output measurements to test for consistency and placement of the probe, and also to get control values for mean arterial pressure and heart rate. The timer on the automatic data collection system was started, and data points were taken at $t_{0}, t_{5}$, $t_{10}, t_{15}, t_{30}, t_{45}$, and $t_{60} \mathrm{~min}$. Hypovolemic hypotension was induced by bleeding through the other arterial line $27 \%$ of the blood volume $\left(5 \mathrm{ml} \cdot 300 \mathrm{~g}^{-1} \cdot 5 \mathrm{~min}^{-1}\right)$. The bleeding was started at $t_{0}$, and the drug injection was made between $t_{5}$ and $t_{10}$, at approximately $t_{8}$. The drugs were injected slowly (over $30 \mathrm{~s}$ ) into the arterial line. Total peripheral resistance was calculated by dividing the mean arterial pressure by the cardiac output; values of cardiac output and TPR were further indexed per unit of weight (kg).

In additional rats the effect of CG3703 on cardiac output and total peripheral resistance was investigated in the conscious state. The rats were anesthetized with pentobarbitone $(40 \mathrm{mg} / \mathrm{kg}$ ip), and the surgical procedures were performed as described above. All vascular lines were tunneled beneath the skin and exteriorized from the back of the neck. The lines were secured by a soft spring wire attached by an adhesive tape collar at the back of the neck and outside of the cage. The experiments were conducted $24 \mathrm{~h}$ after the surgery. Hypovolemic hypotension was induced by bleeding through the arterial line $45 \%$ of the blood volume $\left(8.5 \mathrm{ml} .300 \mathrm{~g}^{-1} .5\right.$ $\mathrm{min}^{-1}$ ), and the recordings of blood pressure, heart rate, and cardiac output were followed in saline- and TRH- treated animals as described above. The $45 \%$ hemorrhage was used in these experiments, because earlier studies in our laboratory have shown that this volume of bleeding results in about $90 \%$ survival in conscious rats. Furthermore, due to the thermodilution method, the animals were volume loaded with at least $3 \mathrm{ml}$ of saline during the experiment.

\section{Regional Blood Flow Measurements With Directional Pulsed Doppler Technique}

Another set of rats $(n=13)$ was used to study the effect of CG3703 on regional blood flow and vascular resistance by the directional pulsed Doppler method. By using this technique we are not able to quantitate the actual blood flow. However, Haywood and co-workers (12) have shown that the velocity signals recorded from the Doppler flow probes are directly and reliably proportional to changes in true volume flow measured by electromagnetic flowmeter. The animals were anesthetized with ketamine-acepromazine, $0.13 \mathrm{ml} / 100 \mathrm{~g}$ of a solution of ketamine $(100 \mathrm{mg} / \mathrm{ml})$ and acepromazine $(1 \mathrm{mg} / \mathrm{ml})$, and miniaturized Doppler flow probes (Valpey-Fisher) were implanted around the abdominal aorta, superior mesenteric artery, and the left renal artery according to the method described earlier (12). Briefly, a midline laparotomy was made, and 4-mm lengths of the lower abdominal aorta below the left renal, the superior mesenteric, and the left renal arteries were carefully isolated with the aid of a dissecting microscope. Miniaturized Doppler flow probes were then sutured around each vessel. The wire leads were tunneled beneath the skin and exteriorized at the nape of the neck where they were soldered to a connector plug that was fixed to the animal's skull with small screws and dental acrylic. Polyethylene catheters (PE-50) were implanted in the femoral arteries for measurements of blood pressure and heart rate and for drug injections. The catheters were led beneath the back skin to exit at the nape of the neck and were then secured by a spring wire as described above. The animals were allowed to recover from the surgery for 2-3 days. On the day of the experiment the rat was connected to the flow probe wire connectors, and the connector line was suspended from the top of the animal's home cage to allow freedom of movement during the experiment. Regional blood flow was measured with a directional pulsed Doppler flowmeter (model 545c-3, University of Iowa Bioengineering Facility). The arterial line was attached to a pressure transducer (as above), and the blood pressure, heart rate, and regional blood flows were continuously recorded on the Narco dynograph. Vascular resistance was calculated by dividing the mean arterial pressure by blood velocity (Doppler shift in $\mathrm{kHz}$ ). Changes in blood flow and vascular resistance are expressed as a percent of control values. Since in these experiments the animals were not volume loaded, the $27 \%$ hemorrhage was chosen. Hypovolemic hypotension was induced by bleeding through the other arterial line $27 \%$ of the blood volume $\left(5 \mathrm{ml} \cdot 300 \mathrm{~g}^{-1} .5 \mathrm{~min}^{-1}\right)$, and saline or CG3703 $(0.5 \mathrm{mg} / \mathrm{kg})$ was injected into the arterial line 2-3 min after bleeding. 


\section{Assay of Blood $\mathrm{CO}_{2}, \mathrm{O}_{2}, \mathrm{pH}$, and Lactates}

In a separate set of rats $(n=18)$ the effects of TRH or CG3703 on blood gases and lactate were studied in conscious rats exposed to $45 \%$ hemorrhage. Arterial lines were implanted into femoral vessels under halothane anesthesia ( $2 \%$ halothane in $\mathrm{O}_{2}$ ) $24 \mathrm{~h}$ before the experiments. Hypovolemic hypotension was induced by bleeding through the arterial line $8.5 \mathrm{ml} .300 \mathrm{~g}^{-1} .5 \mathrm{~min}^{-1}$, and an equal volume of saline, TRH $(2 \mathrm{mg} / \mathrm{kg})$, or CG3703 $(0.5 \mathrm{mg} / \mathrm{kg}$ ) was injected into the arterial line $2-3 \mathrm{~min}$ after the bleeding. The first and the last $0.5 \mathrm{ml}$ of this blood was saved for the assays, and additional $0.5-\mathrm{ml}$ blood samples were withdrawn from the arterial line 30 , 60,90 , and $120 \mathrm{~min}$ after the bleeding. Immediately after the withdrawal of these blood samples, an equal volume of fresh blood from other rats was used to replenish the amount withdrawn. Blood $\mathrm{CO}_{2}, \mathrm{O}_{2}$, and $\mathrm{pH}$ were assayed on whole blood $(0.25 \mathrm{ml})$ using a Corning $\mathrm{pH}$-blood gas $165 / 2$ analyzer. Blood lactate was assayed with a commercial kit (Sigma, St. Louis, MO).

\section{Drugs Used}

The following drugs were used: thyrotropin releasing hormone (TRH) (Sigma) and the degradation-stabilized TRH analogue, CG3703 (6-methyl-5-oxo-thiomorpholinyl-3-carbonyl-histidyl-prolinamide), kindly provided by Dr. Flohé from Grünenthal GmbH, Aachen, FRG, were both dissolved in saline.

\section{Statistical Analysis of the Data}

Data in text and figures are represented as means \pm SEM for the number of rats indicated. Analysis of variance (ANOVA) with repeated measures and ANOVA followed by Student-Newman-Keuls test were both used for statistical analysis of the data. Significance of survival rate was determined by means of Fisher's exact probability test.

\section{RESULTS}

\section{Effects of TRH and CG3703 in Anesthetized Rats}

Effects on blood pressure and heart rate (Fig. 1). Bleeding through a femoral line $\left(5 \mathrm{ml} .300 \mathrm{~g}^{-1} .5 \mathrm{~min}^{-1}\right)$ induced sharp decreases in mean arterial and pulse pressures. Injection of TRH at doses of $0.5 \mathrm{mg} / \mathrm{kg}$ or $2 \mathrm{mg} /$ $\mathrm{kg}$ into the arterial line a few minutes after the bleeding reversed the bleeding-induced hypotension in a doserelated manner. The heart rate significantly increased only after the highest dose of TRH. CG3703 $(0.5 \mathrm{mg} / \mathrm{kg}$ ia) induced short-lasting increments of blood pressure and a delayed tachycardia, whereas the higher dose caused strong sustained rises of blood pressure and heart rate.

Effects on cardiac index and total peripheral resistance index (Fig. 2). Bleeding ( $\left.5 \mathrm{ml} .300 \mathrm{~g}^{-1} \cdot 5 \mathrm{~min}^{-1}\right)$ significantly decreased cardiac index and total peripheral resistance. TRH $(0.5 \mathrm{mg} / \mathrm{kg}$ or $2 \mathrm{mg} / \mathrm{kg}$ ia) dose-dependently reversed the decreases in cardiac index and total
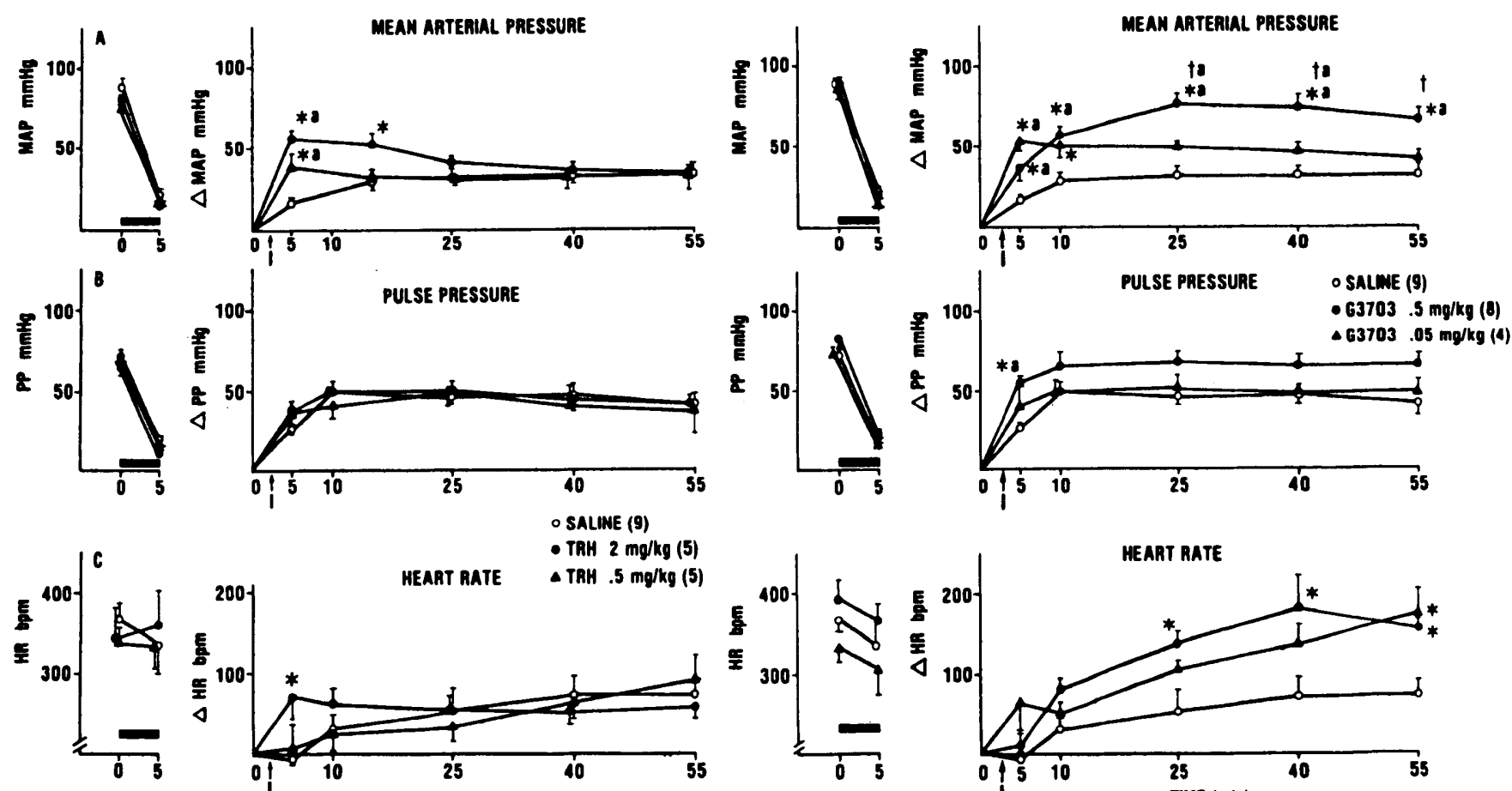

- SALINE (9)

- TAH $2 \mathrm{mg} / \mathrm{kg}(5)$
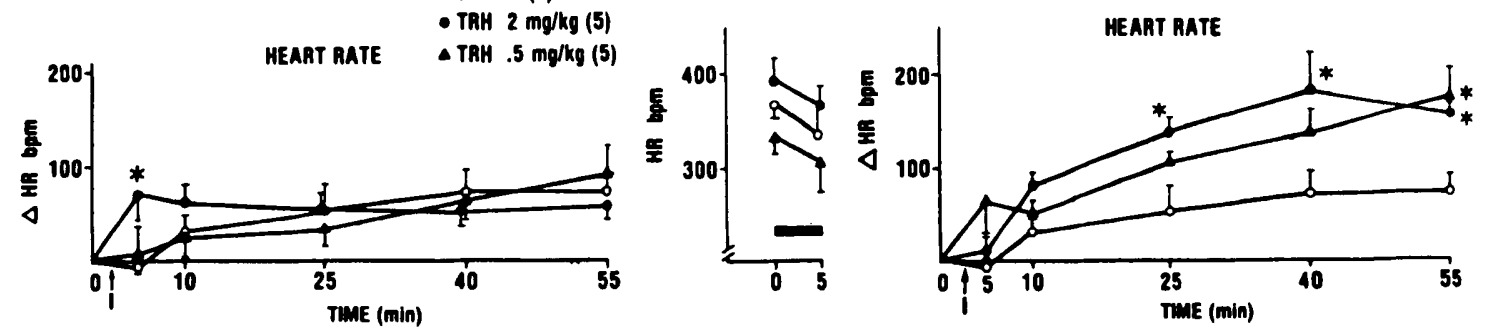

PIG. 1. Effect of thyrotropin releasing hormone (TRH) and TRH analogue CG3703 on cardiovascular variables following hemorrhage $(27 \%)$ in the urethan-anesthetized rat. TRH $(0.5$ or $2 \mathrm{mg} / \mathrm{kg}), \mathrm{CG} 3703(0.05$ or $5 \mathrm{mg} / \mathrm{kg})$, or saline was injected (I, arrow) into the arterial line $2-3 \mathrm{~min}$ after bleeding (5 ml. $\left.300 \mathrm{~g}^{-1} .5 \mathrm{~min}^{-1}\right)$. Values represent means \pm SEM;,$P<0.05$ and $\bullet, P<0.01$ v8. saline-treated group;,$+ P<0.05$ and $+a, P<0.01$ low vs. high dose (Student-Newman-Keuls test). 
TOTAL PERIPHERAL AESISTANCE MDEX
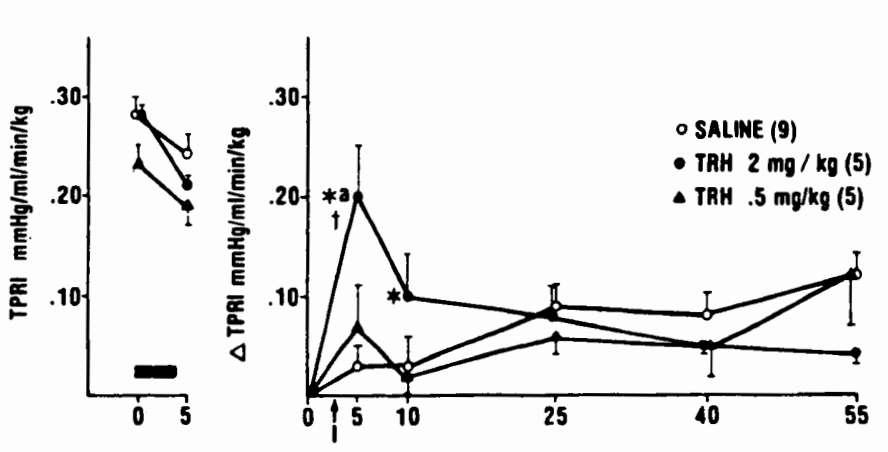

CARDIAC INDEX
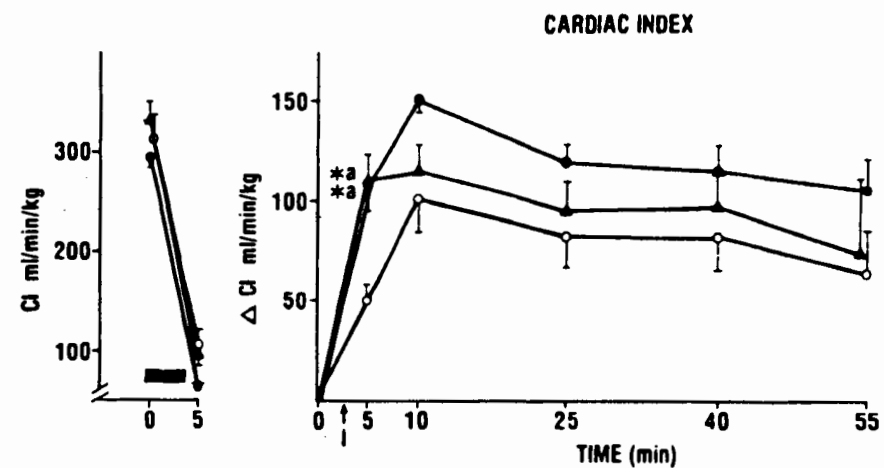
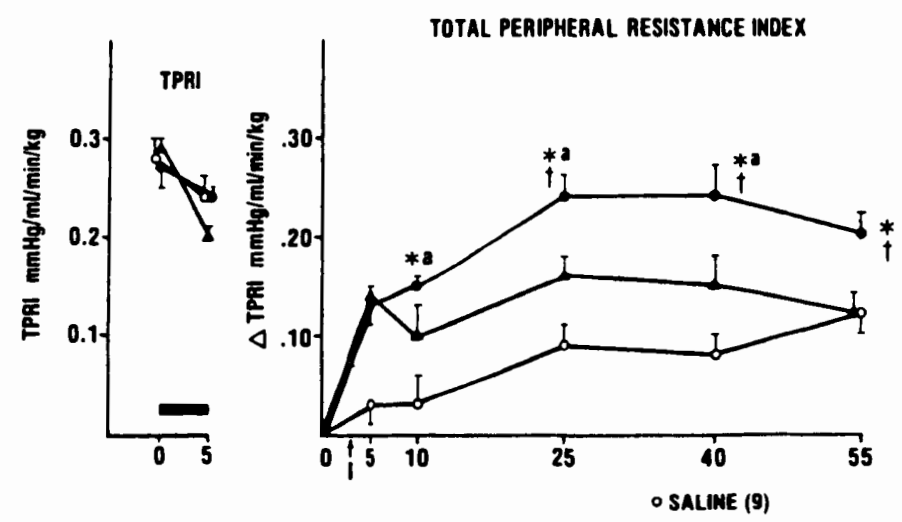

- $63703.5 \mathrm{mg} / \mathrm{kg}(8)$

CAROIAC MNEXX
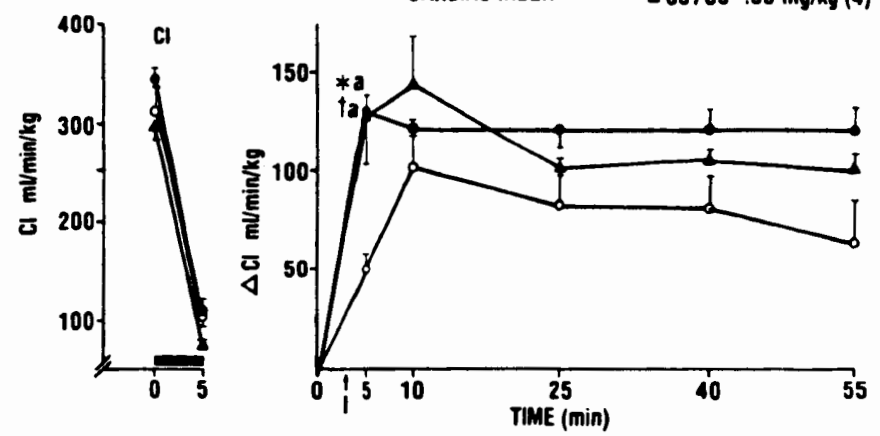

FIG. 2. Effect of thyrotropin releasing hormone (TRH) and TRH analogue CG3703 on cardiac index and total peripheral resistance index following hemorrhage $(27 \%)$ in the urethan-anesthetized rat. TRH $(0.5$ or $2 \mathrm{mg} / \mathrm{kg})$, CG3703 $(0.05$ or $0.5 \mathrm{mg} / \mathrm{kg})$, or saline was injected $(I$, arrow) into the arterial line $2-3$ min after bleeding ( $5 \mathrm{ml} .300$ $\left.\mathrm{g}^{-1} .5 \mathrm{~min}^{-1}\right)$. Values represent means $\pm \mathrm{SEM} ; \quad ; P<0.05$ and ${ }^{\circ} a, P<0.01$ v8. saline-treated group;,$+ P<0.05$ and ta, $P<0.01$ low vs. high dose (Student-Newman-Keuls test).

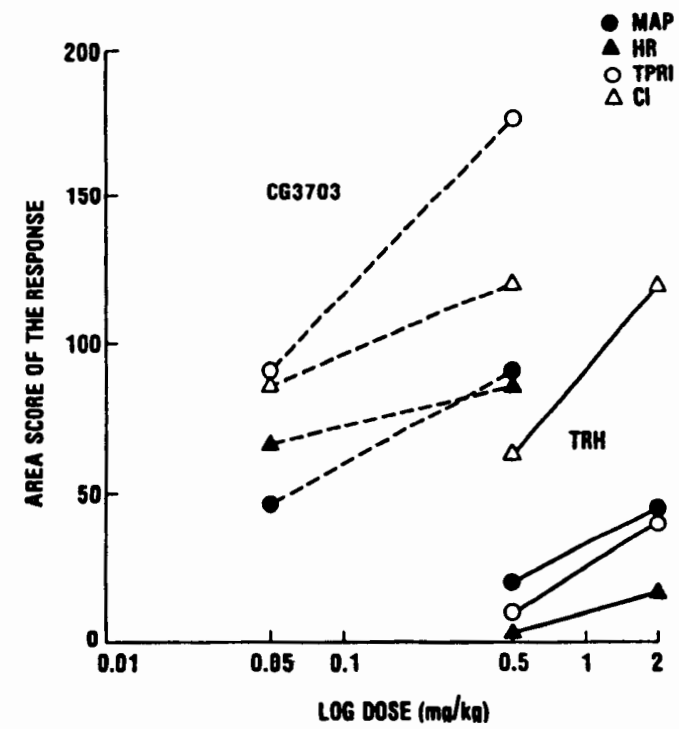

FIG. 3. Dose-response relationship of thyrotropin releasing hormone (TRH) and CG3703 to induce cardiovascular changes in the anesthetized rat exposed to $27 \%$ hemorrhage. Solid lines, TRH; dotted lines, CG3703. Data from Figs. 1 and 2. Area scores represent areas under the time-response curve of the drug in each case. MAP, mean arterial pressure; HR, heart rate; TPRI, total peripheral resistance index; $\mathrm{CI}$, cardiac index.

peripheral resistance index caused by the bleeding. The increase in total peripheral resistance induced by TRH was short-lasting: the maximum rise became apparent a few minutes after the drug injection, and the effect subsided in about 10-25 min. Cardiac index, on the other hand, increased immediately after the drug administration and remained high during the whole observation period $(60 \mathrm{~min})$.

CG3703 $(0.05 \mathrm{mg} / \mathrm{kg}$ or $0.5 \mathrm{mg} / \mathrm{kg})$ injected into the arterial line a few minutes after the bleeding caused a sustained increment in cardiac index and increased total peripheral resistance in a dose-related manner. The relative activity (represented as area score for each variable) of TRH and CG3703 to induce cardiovascular changes in hemorrhaged rats is demonstrated in Fig. 3. Compared with TRH, CG3703 was 10 times more potent in eliciting increases in cardiac index, 15 times more potent in causing rises of mean arterial pressure, 250 times more potent in increasing total peripheral resistance index, and 400 times more potent in producing tachycardia.

\section{Effects of CG3703 in Conscious Rats}

Effects on blood pressure and heart rate (Fig. 4). On the basis of the experiments performed on the anesthetized rats, the $0.5 \mathrm{mg} / \mathrm{kg}$ dose of the TRH analogue, CG3703, was chosen to be used in all studies on conscious animals. Bleeding of the rats via the arterial line $\left(8.5 \mathrm{ml} \cdot 300 \mathrm{~g}^{-1}\right.$. $5 \mathrm{~min}^{-1}$ ) induced sharp decreases in mean arterial and pulse pressures with variable effect on the heart rate. The mean blood pressure after the hemorrhage was $47 \pm$ $3 \mathrm{mmHg}$ in the control group and $54 \pm 5 \mathrm{mmHg}$ in the drug-treated group. The TRH analogue induced a significant reversal of the bleeding-induced hypotension and a long-lasting increase in the heart rate. When given to normotensive rats, CG3703 increased the mean arterial 

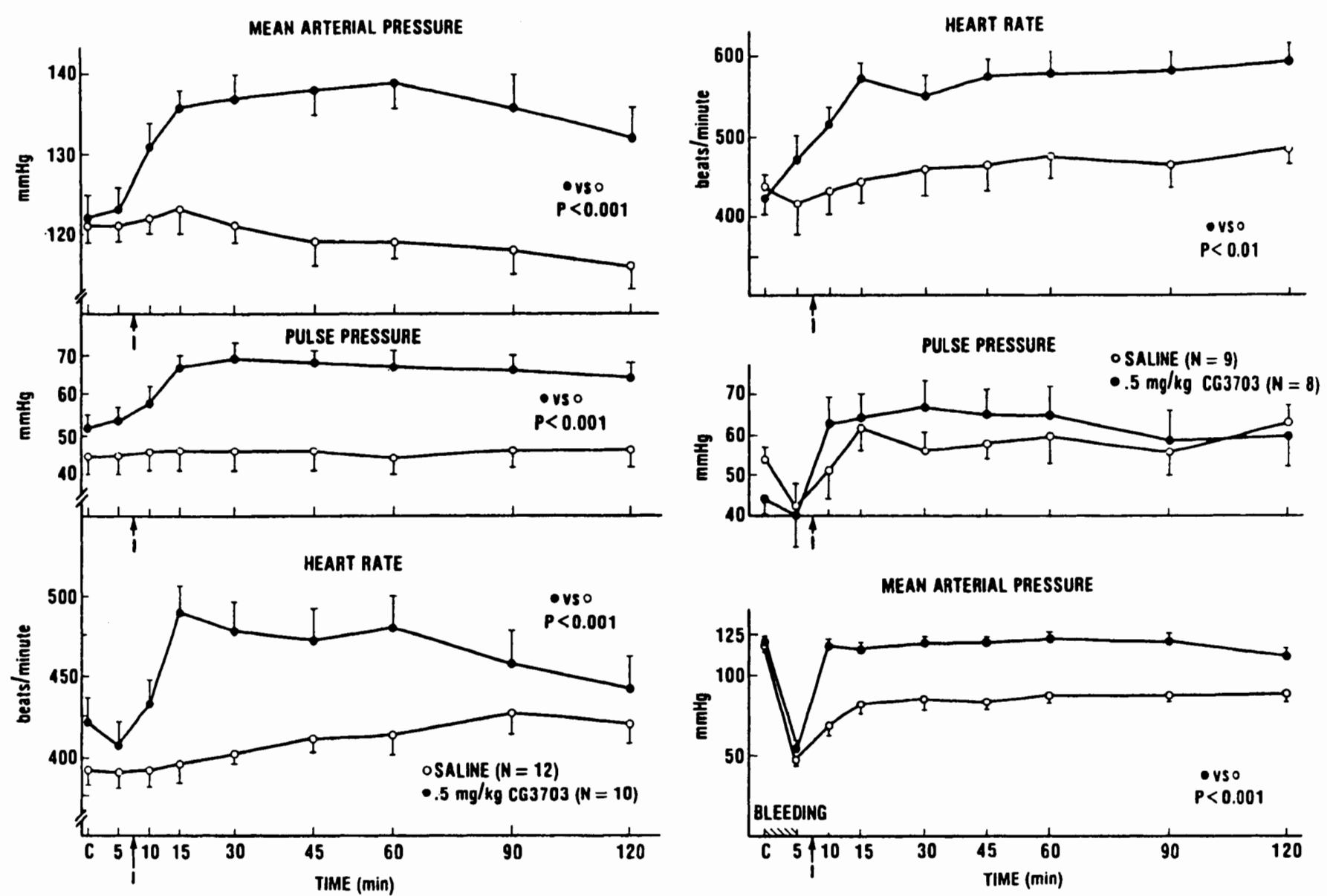

FIG. 4. Effect of thyrotropin releasing hormone (TRH) analogue CG3703 on cardiovascular variables in intact conscious rats and rats exposed to $45 \%$ hemorrhage. CG3703 $(0.5 \mathrm{mg} / \mathrm{kg})$ or saline was injected $(I$, arrow) into the arterial line at $t_{8}$. Values represent means \pm SEM.

pressure, pulse pressure, and heart rate with maximum rises of $+16 \pm 4 \mathrm{mmHg},+15 \pm 3 \mathrm{mmHg}$, and $+84 \pm 15$ beats/min $(P<0.01)$, respectively.

Effects on cardiac index and total peripheral resistance (Fig. 5). Bleeding the rats at a rate of $8.5 \mathrm{ml} \cdot 300 \mathrm{~g}^{-1} \cdot 5$ $\mathrm{min}^{-1}$ caused decreases in cardiac output and peripheral resistance. The drops in cardiac index and total peripheral resistance were $-250 \pm 15 \mathrm{ml} \cdot \mathrm{min}^{-1} \cdot \mathrm{kg}^{-1}$ and -0.04 $\pm 0.01 \mathrm{mmHg} \cdot \mathrm{ml}^{-1} \cdot \mathrm{min}^{-1} \cdot \mathrm{kg}^{-1}$ in the control group and $-230 \pm 25 \mathrm{ml} \cdot \mathrm{min}^{-1} \cdot \mathrm{kg}^{-1}$ and $-0.05 \pm 0.01 \mathrm{~mm} \mathrm{Hg}{ }^{-1}$. $\mathrm{ml}^{-1} \cdot \mathrm{min}^{-1} \cdot \mathrm{kg}^{-1}$ in the drug-treated group. CG3703 $(0.5$ $\mathrm{mg} / \mathrm{kg}$ ia) injected 2-3 min after the end of the bleeding produced a long-lasting rise of total peripheral resistance with no significant improvement in the cardiac index. On the contrary, the recovery of cardiac function was significantly impaired by CG3703 so that the increments of cardiac index $90 \mathrm{~min}$ after the end of the bleeding were $+54 \pm 25 \mathrm{ml} \cdot \mathrm{min}^{-1} \cdot \mathrm{kg}^{-1}(+22 \pm 10 \%)$ in the drugtreated rats and $+129 \pm 25 \mathrm{ml} \cdot \mathrm{min}^{-1} \cdot \mathrm{kg}^{-1}(+60 \pm 15 \%)$ in the control group. The corresponding changes $2 \mathrm{~h}$ after the end of the bleeding were significantly different in CG3703-treated versus control groups $(f=2.43, P=$ 0.02 ). In intact (nonbled) animals the same dose of CG3703 significantly increased the cardiac index but had no significant effect on total peripheral resistance.

Effects on regional blood flow and vascular resistance (Fig. 6). Bleeding at a rate of $5 \mathrm{ml} \cdot 300 \mathrm{~g}^{-1} \cdot 5 \mathrm{~min}^{-1}$ decreased the blood flow in hindquarter, mesenteric, and renal vasculature. In spite of a significant improvement in blood pressure and heart rate, CG3703 $(0.5 \mathrm{mg} / \mathrm{kg}$ ia) significantly enhanced the bleeding-induced impairment of blood flow in all these vascular beds. The blood flows in control versus CG3703-treated rats $2 \mathrm{~h}$ after the bleeding were $-32 \pm 6 \%$ versus $-55 \pm 6 \%(P<0.001)$ in the hindquarters, $-9 \pm 8 \%$ versus $-61 \pm 11 \%(P<$ 0.001 ) in the mesenteric artery, and $-2.9 \%$ versus $-33 \pm$ $9 \%(P<0.01)$ in the renal artery. The corresponding changes in the vascular resistance $2 \mathrm{~h}$ after the bleeding were $+30 \pm 7 \%$ versus $+309 \pm 167 \%$ in the hindquarters $(P<0.001),-4 \pm 8 \%$ versus $+349 \pm 244 \%$ in the mesenteric, and $-10 \pm 9 \%$ versus $+80 \pm 10 \%(P<0.01)$ in the renal artery.

Effect on blood $\mathrm{CO}_{2}, \mathrm{O}_{2}, \mathrm{pH}$, and lactate (Table 1). Bleeding at a rate of $8.5 \mathrm{ml} \cdot 300 \mathrm{~g}^{-1} .5 \mathrm{~min}^{-1}$ induced significant increases in blood lactate and $\mathrm{Po}_{2}$, and significantly decreased blood $\mathrm{PCO}_{2}$, but had no effect on blood pH. Systemic injection of TRH $(2 \mathrm{mg} / \mathrm{kg})$ or CG3703 $(0.5 \mathrm{mg} / \mathrm{kg})$ into the arterial line $2-3 \mathrm{~min}$ after the end of the bleeding significantly attenuated the hyperoxemia produced by hemorrhage but had no effect on blood $\mathrm{pH}, \mathrm{CO}_{2}$, or lactic acid level.

Effect on survival (Table 2). TRH (2 mg/ $\mathrm{kg}$ ia) significantly decreased survival $1 \mathrm{~h}$ after the hemorrhage in the conscious rat, while the TRH analogue, CG3703 $(0.5 \mathrm{mg} /$ 

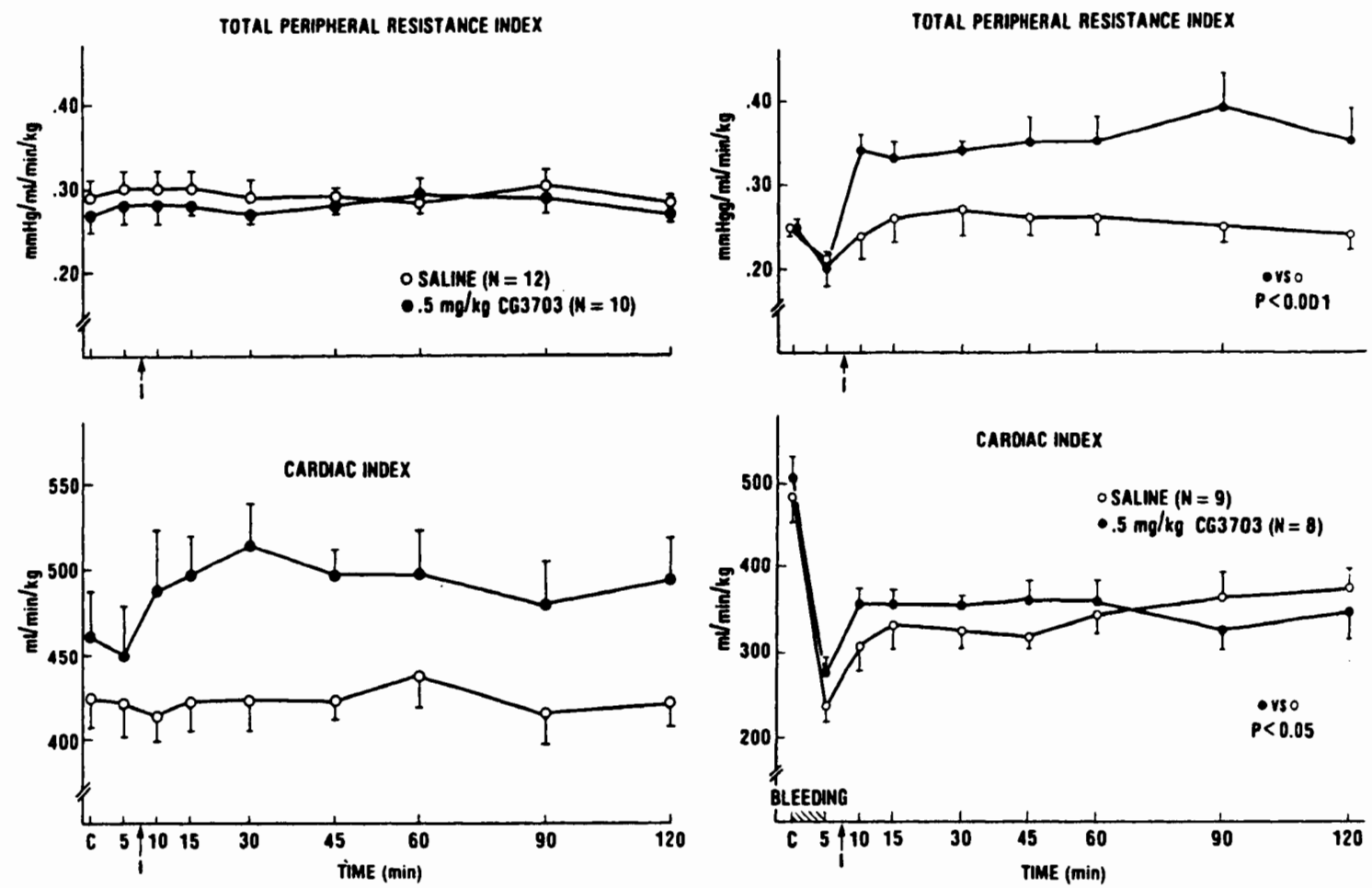

PIG. 5. Effect of thyrotropin releasing hormone (TRH) analogue CG3703 on cardiac index (CI) and total peripheral resistance index in intact conscious rats and rats exposed to $45 \%$ hemorrhage. Saline was injected $(I$, arrow) into the arterial line at $t_{8}$. Values represent means \pm SEM. CG3703-induced increase in $\mathrm{CI}$ was significant at $P<0.05$, compared with control group during 1st 45 min (ANOVA with repeated measures).

$\mathrm{kg}$ ia), induced a significant reduction on the 24-h survival rate after the $8.5 \mathrm{ml} \cdot 300 \mathrm{~g}^{-1} .5 \mathrm{~min}^{-1}$ bleeding.

\section{DISCUSSION}

TRH and its pyroglutamyl analogue CG3703 (10) reversed the bleeding-induced hypotension and increased the heart rate in a dose-related manner in both urethananesthetized and conscious rats. Systemic injection of CG3703 $(0.5 \mathrm{mg} / \mathrm{kg})$ raised blood pressure and heart rate also in the intact conscious rat. Due to its prolonged action, CG3703 was more potent than TRH in inducing cardiovascular changes. Earlier studies have shown that the long-lasting biological activity of CG compounds is due to their resistance to the TRH degradating pyroglutamate aminopeptidases (10).

TRH is known to be a potent pressor and tachycardic agent in anesthetized $(5,16)$ and conscious rats (8). These actions of TRH were believed to underlie the improved cardiovascular function in various experimental shock models including the hypovolemic shock (for review see Ref. 3). The cardiovascular effects of TRH are likely to be due to an action of the agent on the central nervous system, since the doses needed to elicit cardiovascular changes after systemic injections are a thousandfold higher than the doses used intracerebroventricularly or for injections into discrete brain nuclei $(5,8,14,16)$. A peripheral component in the beneficial cardiovascular effects of TRH in endotoxic shock has also been suggested, since the pressor and tachycardic effects of centrally administered TRH in this particular shock model were partly blocked by adrenal medullec- tomy, whereas the effects of systemically injected TRH remained unaffected (14). However, a peripheral mechanism of action of TRH is contradicted by the recent finding that the reversal of LTD $_{4}$-induced hypotension by TRH is totally abolished in the pithed rat, in which the entire central nervous system and cardiac reflexes are eliminated (9).

Concomitantly with the reversal of hypovolemic hypotension, TRH and the analogue, CG3703, dose-dependently antagonized the bleeding-induced decline in cardiac index and markedly increased total peripheral resistance in the urethan-anesthetized rat. The cardiovascular changes caused by TRH were relatively shortlasting, whereas CG3703, at the highest dose, produced prolonged increases in blood pressure, heart rate, and total peripheral resistance but only a brief elevation of cardiac index. The increase in cardiac index by CG3703 in anesthetized rats might be due to antagonism by TRH analogues of the effects of anesthesia $(19,20)$, since in the conscious rat exposed to the hemorrhage the TRH analogue, CG3703, caused a marked, prolonged increase in vascular resistance with no beneficial effect on the cardiac index. This is further supported by the fact that the base-line levels for cardiac index were significantly reduced by anesthesia as reported also by others earlier (22). Furthermore, in conscious rats, CG3703 significantly delayed the recovery of cardiac function after the bleeding.

In conscious intact rats CG3703 induced the pressor and tachycardic responses that were accompanied by an increase in cardiac index while total peripheral resistance remained unchanged. Studies in progress in our labora- 

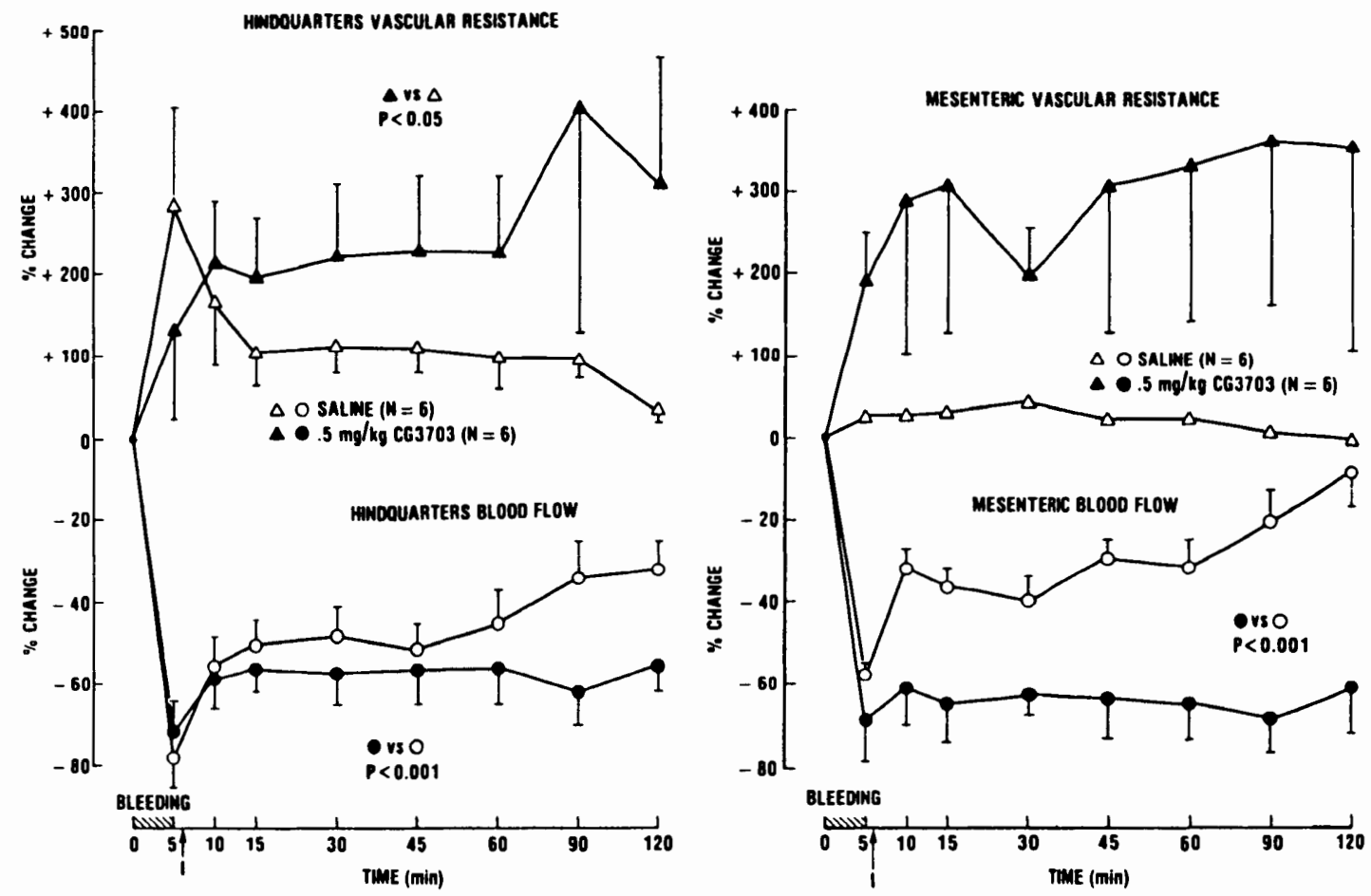

BEHAL VASCULAR RESISTANCE

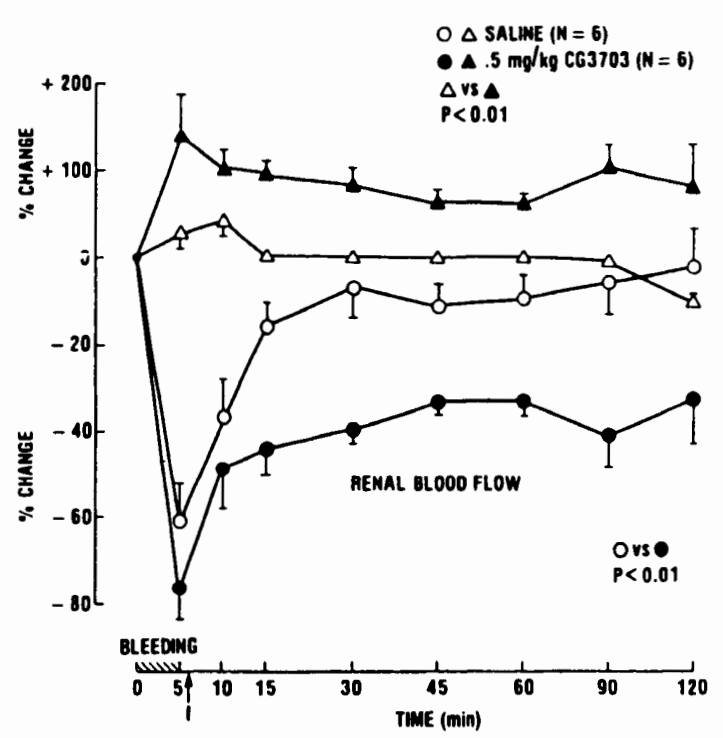

FIG. 6. Effect of thyrotropin releasing hormone (TRH) analogue CG3703 on regional blood flow and vascular resistance in hindquarter, mesenteric, and renal vascular beds following hemorrhage (27\%) in the conscious rat. CG3703 $(0.5 \mathrm{mg} / \mathrm{kg})$ or saline was injected $\left(I\right.$, arrow) into the arterial line $2-3$ min after bleeding $\left(5 \mathrm{ml} \cdot 300 \mathrm{~g}^{-1}\right.$. $\left.\min ^{-1}\right)$. Values represent means \pm SEM.

tory (unpublished observations) confirmed this special pattern of hemodynamic changes also after systemic injection of TRH $(2 \mathrm{mg} / \mathrm{kg} \mathrm{ia})$ in the normovolemic conscious rat. Thus the hemodynamic mechanisms underlying the pressor effect of TRH in hypovolemic hypotension seem to differ from those mediating its hypertensive response in the normovolemic state. The marked reduction of blood volume caused by the bleeding $(45 \%)$ and/or by the excessive increase in afterload to the heart due to the strongly elevated vascular resistance by TRH may account for these differences.

The present findings on the effect of CG3703 on the blood flow further support this view: in conscious rats exposed to a $27 \%$ hemorrhage, the TRH analogue, CG3703, significantly enhanced the bleeding-induced impairment of local blood flow in hindquarter, mesenteric, and renal vasculature, and strongly increased the vascular resistance in hindquarter and renal and, to a lesser degree, in mesenteric vasculature. In the intact rat we recently reported increased blood flow in hindquarter 
TABLE 1. Effect of TRH and CG3703 on blood gases, $p H$, and lactic acid following $45 \%$ hemorrhage in conscious rat

\begin{tabular}{|c|c|c|c|c|c|c|c|}
\hline & \multirow{2}{*}{$n$} & \multirow{2}{*}{$\mathrm{C}$} & \multirow{2}{*}{ EOB } & \multicolumn{4}{|c|}{ Minutes After EOB } \\
\hline & & & & 30 & 60 & 90 & 120 \\
\hline Saline & \multirow[t]{5}{*}{5} & & & & & & \\
\hline $\mathrm{pH}$ & & $7.47 \pm 0.01$ & $7.48 \pm 0.03$ & $7.45 \pm 0.03$ & $7.46 \pm 0.03$ & $7.46 \pm 0.03$ & $7.44 \pm 0.02$ \\
\hline $\mathrm{PCO}_{2}, \mathrm{mmHg}$ & & $30 \pm 1$ & $18 \pm 1$ & $24 \pm 1$ & $26 \pm 2$ & $27 \pm 2$ & $28 \pm 2$ \\
\hline $\mathrm{Po}_{2}, \mathrm{mmHg}$ & & $92 \pm 3$ & $125 \pm 1$ & $126 \pm 3$ & $125 \pm 3$ & $123 \pm 2$ & $123 \pm 3$ \\
\hline Lactic acid, $\mathrm{mmol} / \mathrm{]}$ & & $1.3 \pm 0.2$ & $7.2 \pm 1.0$ & $4.9 \pm 0.3$ & $4.1 \pm 0.7$ & $3.1 \pm 0.6$ & $2.8 \pm 0.6$ \\
\hline $\mathrm{TRH}, 2 \mathrm{mg} / \mathrm{kg}$ & \multirow[t]{5}{*}{7} & & & & & & \\
\hline $\mathrm{pH}$ & & $7.44 \pm 0.01$ & $7.47 \pm 0.02$ & $7.45 \pm 0.01$ & $7.44 \pm 0.01$ & $7.43 \pm 0.01$ & $7.44 \pm 0.01$ \\
\hline $\mathrm{PCO}_{2}, \mathrm{mmHg}$ & & $32 \pm 1$ & $21 \pm 1$ & $26 \pm 2$ & $27 \pm 1$ & $29 \pm 1$ & $30 \pm 1$ \\
\hline $\mathrm{PO}_{2}, \mathrm{mmHg}$ & & $93 \pm 3$ & $129 \pm 4$ & $112 \pm 4^{*}$ & $113 \pm 4$ & $108 \pm 2 \dagger$ & $102 \pm 3 t$ \\
\hline Lactic acid, mmol/1 & & $1.4 \pm 0.1$ & $6.8 \pm 0.4$ & $4.9 \pm 0.6$ & $3.6 \pm 0.5$ & $2.8 \pm 0.4$ & $2.4 \pm 0.2$ \\
\hline CG3703, $0.5 \mathrm{mg} / \mathrm{kg}$ & \multirow[t]{5}{*}{5} & & & & & & \\
\hline $\mathrm{pH}$ & & $7.45 \pm 0.01$ & $7.43 \pm 0.03$ & $7.44 \pm 0.01$ & $7.46 \pm 0.03$ & $7.47 \pm 0.02$ & $7.48 \pm 0.03$ \\
\hline $\mathrm{PCO}_{2}, \mathrm{mmHg}_{\mathrm{g}}$ & & $32 \pm 1$ & $21 \pm 2$ & $23 \pm 1$ & $22 \pm 2$ & $24 \pm 2$ & $23 \pm 3$ \\
\hline $\mathrm{Po}_{2}, \mathbf{m m H g}$ & & $86 \pm 2$ & $118 \pm 5$ & $110 \pm 2 \dagger$ & $117 \pm 5$ & $108 \pm 1 \dagger$ & $108 \pm 3 \dagger$ \\
\hline Lactic acid, mmol/1 & & $1.3 \pm 0.3$ & $7.5 \pm 1.3$ & $5.9 \pm 0.8$ & $5.2 \pm 0.8$ & $4.5 \pm 0.8$ & $3.7 \pm 0.6$ \\
\hline
\end{tabular}

Values are means \pm SEM. TRH, thyrotropin releasing hormone; CG3703, analogue of TRH; EOB, end of bleeding; C, control period before hemorrhage. TRH, CG3703 or saline was injected into the arterial line 2-3 min after bleeding $8.5 \mathrm{ml}^{\circ} 300 \mathrm{~g}^{-1} \cdot 5 \mathrm{~min}^{-1}$. $P<0.05$; $+P<0.01$ vs. saline-treated group (Student-Newman-Keuls test).

TABLE 2. Effect of TRH and CG3703 on survival in conscious rats exposed to hemorrhage

\begin{tabular}{|c|c|c|c|c|c|c|}
\hline \multirow{2}{*}{ Treatment } & \multicolumn{3}{|c|}{$\begin{array}{c}\text { 45\% Hemorrhage, } \\
\text { h After EOB }\end{array}$} & \multicolumn{3}{|c|}{$\begin{array}{c}27 \% \text { Hemorrhage, } \\
\text { h After EOB }\end{array}$} \\
\hline & 1 & 2 & 24 & 1 & 2 & 24 \\
\hline $\begin{array}{l}\text { Saline } \\
\text { TRH, } \\
2 \mathrm{mg} / \mathrm{kg} \text { ia }\end{array}$ & $\begin{array}{c}17 / 0 \\
8 / 3^{*}\end{array}$ & $\begin{array}{r}14 / 3 \\
7 / 4\end{array}$ & $\begin{array}{r}13 / 4 \\
7 / 4\end{array}$ & $\begin{array}{l}7 / 0 \\
\mathrm{NT}\end{array}$ & $\begin{array}{l}7 / 0 \\
\mathrm{NT}\end{array}$ & $\begin{array}{l}6 / 0 \\
\text { NT }\end{array}$ \\
\hline $\begin{array}{l}\text { CG3703, } \\
0.5 \mathrm{mg} / \mathrm{kg} \text { ia }\end{array}$ & $17 / 3$ & $13 / 7$ & $7 / 13 \dagger$ & $7 / 1$ & $6 / 2$ & $5 / 3$ \\
\hline
\end{tabular}

Values are survival ratios (alive/dead). TRH, thyrotropin releasing hormone; EOB, end of bleeding; NT, not tested. Drugs were injected into the arterial line 2-3 min after EOB. ${ }^{*} P=0.05 ; \quad+P=0.01$ vs. saline-treated group (Fisher's exact probability test).

and reduced perfusion in renal (and to a lesser degree in mesenteric) vascular beds with opposite changes in vascular resistance after intracerebroventricular $(0.8-80$ $\mathrm{nmol} / \mathrm{kg}$ ) or intravenous $(2 \mathrm{mg} / \mathrm{kg}$ ) injections of $\mathrm{TRH}$ (23). Thus these differential effects of TRH on local blood flow and vascular resistance in intact versus hemorrhaged animals may, at least in part, explain the discrepancy in its hemodynamic effects in normovolemic versus hypovolemic state. In hypovolemic hypotension TRH further increased the bleeding-induced impairment of local blood flow to essential organs and increased vascular resistance. The general vascular constriction led to the elevation of total peripheral resistance and mean arterial pressure.

Hemorrhage (45\%) induced complex derangements of blood chemistry; blood lactate levels increased, and blood $\mathrm{PCO}_{2}$ decreased, while there was no significant change in blood $\mathrm{pH}$. This might be due to the opposing effects of lactic acidosis and respiratory alkalosis caused by hyperventilation. Furthermore, due to the hyperventilation, the blood $\mathrm{Po}_{2}$ significantly increased after the bleeding. The hyperoxemia in the saline-treated animals was seen throughout the experimental period of $2 \mathrm{~h}$, whereas, in the TRH- or CG3703-treated rats, the $\mathrm{PO}_{2}$ levels decreased rapidly after the hemorrhage, reaching almost the prehemorrhage level within $2 \mathrm{~h}$ after the end of the bleeding. This might further contribute to the detrimental effect of TRH and its analogue in hemorrhage. Furthermore, the TRH analogue, CG3703, had a moderate cardiodepressant effect in conscious rats exposed to bleeding. The reduction in cardiac output could cause impairment of ventilation-to-perfusion ratio, thereby diminishing the amount of $\mathrm{O}_{2}$ supplied to tissues. The decrease in tissue $\mathrm{O}_{2}$ supply might then, together with the impairment of regional blood flow in vital organs, explain the increased mortality in the $45 \%$ hemorrhage both after native TRH or CG3703.

Though the beneficial effect of TRH on blood pressure in various experimental shock models is well known (for review see Ref. 3), very few studies are available that report the effect of TRH on survival rate in these shock models. Holaday et al. (15) reported increased short-term survival ( $2 \mathrm{~h}$ after the shock) by TRH in endotoxic shock in the rat but had no data about the survival rates in hemorrhagic shock (13). Some preliminary studies on primates $(11,21)$, on the other hand, suggest a beneficial effect of TRH on survival in hemorrhagic, but not in endotoxic, shock. Recently, a drastic increase in survival by centrally injected TRH was reported in anaphylactic shock in mice (1). Our present results clearly show that the TRH analogue, CG3703, significantly decreased survival rate in hypovolemic hypotension $24 \mathrm{~h}$ after the bleeding, while the short-acting natural TRH caused a decline in survival only $1 \mathrm{~h}$ after the bleeding. These findings may suggest that the beneficial effect of TRH is dependent on the shock model as well as on the species studied. Thus TRH and stable analogues may prove to be beneficial in anaphylactic shock, whereas in hypovolemia TRH reverses the hypotension mainly by increasing vascular resistance which leads to a sustained reduction in blood flow to vital organs thereby exacerbating the shock and promoting death.

The authors thank Ferne Robinson and Heidi Hatton for their help in preparing this manuscript.

This work was supported in part by Uniformed Services University of Health Sciences Protocol R09211. 
The opinions or assertions contained herein are the private ones of the authors and are not to be construed as official or reflecting the view of the Department of Defense or the Uniformed Services University of the Health Sciences. The experiments reported herein were conducted according to the principles set forth in the "Guide for the Care and Use of Laboratory Animals," Institute of Laboratory Animal Resources, National Research Council (DHEW Publication no. NIH 78-23, 1978).

Received 17 June 1985; accepted in final form 21 January 1986.

\section{REFERENCES}

1. Amir, S., M. HaRel, AND A. Schachar. Thyrotropin-releasing hormone (TRH) improves survival in anaphylactic shock: a central effect mediated by the sympatho-adrenomedullary $\beta$-adrenoceptive system. Brain Res. 298: 219-224, 1984.

2. Beale, J. S., R. P. White, and S.-P. Huang. EEG and blood pressure effects the TRH in rabbits. Neuropharmacology 16: 499$506,1977$.

3. Bernton, E. W., J. B. Long, and J. W. Holaday. Opiods and neuropeptides: mechanism in circulatory shock. Federation Proc. 44: 290-299, 1985.

4. BROWN, M. R. Thyrotropin releasing factor: a putative CNS regulator of the autonomic nervous system. Life Sci. 28: 1789-1795, 1981.

5. DIZ, I. D., AND K. M. JACOBOwITZ. Cardiovascular effects produced by injections of thyrotropin-releasing hormone in specific preoptic and hypothalamic nuclei in the rat. Peptides 5: 801-808, 1984.

6. FADEN, A. I. Neuropeptides in shock and CNS injury: potential clinical applications. In: The Pharmacologic Approach to the Critically Ill Patient. Baltimore, MD: Williams \& Wilkins, 1983, p. 636649.

7. Feuerstein, G., W. E. LuX, JR., D. Ezra, E. C. Hayes, F. SNYDER, AND A. I. FADEN. Thyrotropin releasing hormone blocks the hypotensive effects of platelet activating factor in the unanesthetized guinea pig. J. Cardiovasc. Pharmacol. 7: 335-340, 1985.

8. Feuerstein, G., A. H. Hassen, and A. I. Faden. TRH: cardiovascular and sympathetic modulation in brain nuclei of the rat. Peptides 4: 617-620, 1983.

9. Feuerstein, C., Z. Zukowska-Grojec, M. BAyorh, I. J. Kopin, AND A. I. FADEN. Leukotriene $D_{4}$-induced hypotension is reversed by thyrotropin releasing hormone. Prostaglandins 26: 711-724, 1983.

10. Friderichs, E., E. Schwertner, S. Herrling, W.-A. Gonzler, F. OTTING, AND L. Floke. Activity of thyroliberin analogs with a modified pyroglutamyl residue on the central nervous system. In: Structure and Activity of Natural Peptides. Berlin: Gruyter, 1981, p. 461-481.

11. GuRll, N. J., D. G. Reynolds, J. Holaday, and E. Ganes. Improved cardiovascular function and survival using thyrotropin releasing hormone (TRH) in primate hemorrhagic shock (Abstract). Physiologist 25: 342, 1982.

12. HAYwood, J. R., R. A. Shaffer, C. FAstenow, G. D. Fink, AND M. J. BRODY. Regional blood flow measurement with pulsed Doppler flowmeter in conscious rat. Am. J Physiol. 241 (Heart Circ. Physiol. 10): H273-H278, 1981.

13. Holaday, J. W., R. J. D'Amato, and A. I. FAdEN. Thyrotropinreleasing hormone improves cardiovascular function in experimental endotoxic and hemorrhagic shock. Science Wash. DC 213: 216$218,1981$.

14. HoladAY, J. W., AND A. I. FADEN. Thyrotropin releasing hormone: autonomic effects upon cardiorespiratory function in endotoxic shock. Reg. Peptides 7: 111-125, 1983.

15. Holaday, J. W., B. A. Ruvio, and A. I. FAden. Thyrotropinreleasing hormone improves blood pressure and survival in endotoxic shock. Eur. J. Pharmacol. 74: 101-105, 1981.

16. KoIvusalo, F., I. PAAKKaRI, J. LEPPÁlUOTO, AND H. KARPPANEN. The effect of centrally administered TRH on blood pressure, heart rate and ventilation in rat. Acta Physiol. Scand. 106: 83-86, 1979.

17. LUX, W. E., JR, G. Feuerstein, AND A. I. FADEN. Alteration of leukotriene $D_{2}$ hypotension by thyrotropin releasing hormone. Nature Lond. 302: 822-824, 1983.

18. LuX, W. E., JR., G. FEUERSTEIN, AND A. I. FADEN. Thyrotropin releasing hormone reverses experimental anaphylactic shock through non endorphin related mechanism. Eur. J. Pharmacol. 90: 301-302, 1983.

19. Metcalf, G. Regulatory peptides as a source of new drugs-the clinical prospects for analogues of TRH which are resistant to metabolic degradation. Brain Res. Rev. 4: 389-408, 1982.

20. PrasAd, C. Thyrotropin-releasing hormone. In: Handbook of Neurochemistry. New York: Plenum, 1985, p. 175-200.

21. Reynolds, D. G., N. J. GuRle, J. Holaday, and E. Ganes. Thyrotropin releasing hormone (TRH) in primate endotoxic shock (Abstract). Physiologist 25: 309, 1982.

22. Salgado, M. C. D., and E. M. KRIEger. Cardiac output in unrestrained conscious rats. Clin. \& Exp. Pharmacol. Physiol., Suppl. 3: 165-167, 1976.

23. SiRÉN, A.-L., AND G. FEUERSTEIN. Effect of thyrotropin releasing hormone on blood pressure and peripheral blood flow in conscious rats (Abstract). Federation Proc. 44: 721, 1985.

24. Watanabe, K., K. T. Nisho, C. MORI, M. Kihara, and Y. YAMORI. Measurement of cardiac output by the thermodilution method in conscious spontaneously hypertensive rats. Jpn. Heart J. 25: 1051-1058, 1984. 